\title{
COMPOSITION AND IMPACT OF REASONS FOR NONCOMPLETION IN CONSTRUCTION PROJECTS
}

\author{
Camilo Ignacio Lagos ${ }^{1}$ and Luis Fernando Alarcón ${ }^{2}$
}

\begin{abstract}
The Last Planner® System (LPS) uses short systematic cycles of work preparation, shortterm execution commitments and identification of Reasons for Noncompletion (RNCs). LPS based software capture quantifiable information that allows to assess RNC impact on execution. RNCs can be categorized using detailed information and their impact can be obtained assessing task progress and compliance. This research aims to determine the main categories, sources and responsible parties affecting compliance, based on empirical data from 25 High-rise Building (HR) and 25 Industrial Construction (IC) projects. Weekly project information representing 22.636 RNCs was assessed to categorize each RNC by type, source and party. The task, commitment and progress information were used to determine their frequency and impact, based on the duration of the affected task and differences between committed and actual progress. The RNC categories were compared across the sample and between HR and IC projects using statistical analyses. Results showed that approximately two in every three RNCs correspond to factors controllable by the main contractor, while collaboration with the client and subcontractors could allow preventing up to $90 \%$ of noncompliance issues.
\end{abstract}

\section{KEYWORDS}

Last Planner® System, standardization, reasons for noncompletion, collaboration, reliable promising.

\section{INTRODUCTION}

The Last Planner® System (LPS) has been used to manage construction projects in multiple countries for over 28 years (Ballard \& Tommelein, 2016). LPS stablishes short cycles of work preparation, commitment, execution and compliance assessment (Alsehaimi et al., 2014) and its use provides quantitative and qualitative information to allow continual improvement on a short-term basis. Its implementation has proven beneficial to increase planning reliability, workflow stabilization, performance across execution and outcomes (Daniel et al., 2015). Also, recent research has found statistically significant correlations between adoption levels, LPS metrics and project performance (Lagos et al., 2019).

1 Ph.D. Student, School of Engineering, Pontificia Universidad Católica de Chile, colagos@uc.cl, orcid.org/0000-0002-0648-0039

2 Professor, School of Engineering, Pontificia Universidad Católica de Chile, lalarcon@ing.puc.cl, orcid.org/0000-0002-9277-2272 
Quantitative research has been limited by the lack of large standardized data samples and, hence, has focused primarily on compliance metrics such as the Percent Plan Complete (PPC) and its relationship to performance (Daniel et al., 2015). Nevertheless, the increasing adoption of IT support systems based on LPS has provided more information, including intermediate planning, work preparation, RNCs and corrective actions, which could be used quantitatively to assess other LPS dimensions (Faloughi et al., 2014). Most LPS research focused on finding causes and sources of noncompliance has relied on single case study analyses or indirect means such as perception surveys to gather information (Daniel et al., 2015). But, most LPS software can allow to standardize and link information, thus, providing ways to use qualitative information such as RNCs in a quantitative way by linking them to performance metrics (Faloughi et al., 2014; Feliz et al., 2014; Lagos et al., 2019). Software like IMPERA automatically link constraints and RNCs to tasks at certain short-term periods, therefore, their impact can be calculated by retrieving short-term performance information for each task (Lagos et al., 2020). This research aims to quantify the frequency and impact of standardized RNC categories to determine where should practitioners and researchers focus the implementation of corrective and preventive actions and how can collaboration help prevent recurring issues.

\section{LITERATURE RESEARCH}

Many authors have covered the causes of project deviation throughout the years (Arditi et al., 1985; Assaf \& Al-Hejji, 2006; Prasad \& Vasugi, 2017). International studies have found that 50 to $70 \%$ of projects experience time overruns ranging from $10 \%$ to $30 \%$ (Assaf \& Al-Hejji, 2006; Ullah et al., 2017). Transversal studies based on interviews and surveys have found over 70 empirical causes of deviation (Akinsiku \& Akinsulire, 2012; Sambasivan \& Soon, 2007), grouped into 10 major categories: Inexperience, Interference, Lack of Resources, Labour Productivity, Design, Financing, Planning, Lack of Compliance of Subcontractors, Equipment and Communication (Sambasivan \& Soon, 2007). Theoretical frameworks based on literature reviews of causes of deviation, sources and effects have found that the 42 main cited causes can be attributed to 8 sources that largely correspond to the aforementioned categories, involving clients, contractors, external sources and third parties, which correspond to suppliers of resources, information or conditions (Ullah et al., 2017).

These sources exhibit a direct correspondence to the seven flows presented identified in the Lean Construction perspective: Information, People, Materials, Equipment, Space, Prior Work and External Conditions (Henrich et al., 2007). In fact, LPS research has shown that failure to assess the seven flows at the Lookahead Planning stage reduces the number of executable tasks, which in turn, decreases planning reliability (Ballard \& Tommelein, 2016; Bortolazza \& Formoso, 2006). A quantitative analysis of 133 projects showed that the impact of workforce shortage, planning and worksite conditions on performance can be traced to deficiencies in constraint management or the removal of RNC sources through corrective actions (Bortolazza \& Formoso, 2006). Another study regarding 69 projects showed that $81 \%$ of the projects' RNCs were caused by internal controllable factors (Formoso \& Moura, 2009).

LPS, which is based on the Lean Construction philosophy, promotes workflow stabilization to reduce waste and improve performance (Ballard \& Tommelein, 2016). It stablishes systematics cycles where tasks are assessed in advance to determine if they lack some of the seven prerequisite conditions. If so, a constraint is identified, managed and removed to make that task executable. The set of executable tasks conforms the 
Workable Inventory, which is used to stablish short-term execution commitments. Compliance is assessed at the end of each short-term period, through the use of the PPC indicator, to determine workflow reliability and, if any task did not fulfil its commitment, it will be assigned a RNC, which corresponds to a rupture in any of the seven production flows (Ballard et al., 2009).

LPS implementation must follow 5 principles (Ballard et al., 2009): (1) Planning detail only increases when needed to plan, prepare, commit or execute tasks, (2) Planning must be a collaborative effort, (3) Upcoming work is pulled by removing constraints, (4) commitments are traced to assess reliability, and (5) the sources of recurring problems should be systematically removed. These principles are implemented through 5 LPS components (Ballard \& Tommelein, 2016): Lookahead Planning, constraint management and work preparation, short-term planning, Reliability assessment and collection of RNCs, and implementation of corrective actions.

Researchers have found that most projects exhibit partial LPS implementations, focusing mainly on the second and fourth components of the methodology (Dave et al., 2015). Hence, project teams are able to stablish commitments collaboratively, monitor compliance and variability, register RNCs and their sources. Although, they lack attention to two key stages: Assessing the needs for effective work preparation through constraint management; and assessing the main sources of recurring problems to focus corrective actions (Lagos et al., 2019). Deficiencies in the implementation of the third and fifth components has been attributed to three factors: Lack of understanding of their relevance; lack of time or resources to collect and assess that information; and lack of standard metrics to assess them (Daniel et al., 2015).

The scarcity of complete implementations, lack of standardized data and effort required to collect it, has forced researchers to focus either on case-study approaches or the use indirect means like surveys and interviews to assess the relationships between LPS components and performance (Brady et al., 2011; Daniel et al., 2015; Dave et al., 2015). Despite those limitations, researchers have found that the increasing LPS adoption leads to performance improvements (Hamzeh \& Aridi, 2013), and contributes to aspects such as planning, workforce and site management, collaboration between parties and waste reduction (Alsehaimi et al., 2014). Case study research has also signalled the relevance of weekly collaborative meetings to empower the work-force in stablishing reliable commitments, removing constraints and preventing RNC sources (Soares et al., 2002). Although, researchers have also found that collaboration tends to focus mainly in stablishing short-term commitments instead of the assessment and implementation of work-preparation and RNC reduction actions (Gao \& Low, 2014).

Recent research has showed that the use of LPS based support software aids to capture, process and use more information in a standardized and systematic way, especially regarding constraint and RNC management (Faloughi et al., 2014; Lagos et al., 2019). These systems automate data processing to deliver information through graphs and panels, which facilitate their analysis (Dave et al., 2010). Using visual information to promote communication has shown benefits in key processes such as constraint identification, onsite coordination and RNC assessment (Tayeh et al., 2019). This has also contributed to the collection of standardized project samples with quantifiable information regarding elements such as constraints, commitments, RNCs and progress (Faloughi et al., 2014; Feliz et al., 2014; Lagos et al., 2020). Transversal quantitative studies carried out with these samples has allowed to determine statistically significant correlations between constrain management, short-term compliance, RNC occurrence, cost and time 
performance (Kim, 2019; Lagos et al., 2019). Also, exploratory research showed that quantitative metrics based on constraints and RNC information exhibit correlations with LPS compliance and performance metrics, so that they can be used to assess management and execution performance (Kim, 2019; Lagos et al., 2019, 2020).

\section{METHODOLOGY}

The review of over 120 papers published between 1985 and 2020, regarding (1) Causes and sources of deviation and (2) LPS implementation, allowed to determine the opportunity to use standardized project information quantitatively to assess the frequency and impact of RNCs. The use of the software IMPERA was selected since it was developed by the Pontificia Universidad Católica de Chile to support LPS implementation and research (Alarcón \& Calderón, 2003). Previous research signalled that most RNCs are caused by internally controllable factors (Formoso \& Moura, 2009), hence, the hypothesis "Most RNCs are caused by internally controllable sources" was formulated. Three research questions were established: (1) Which are the most relevant types of RNCs affecting projects which use the Last Planner® System? (2) what is the relative impact of different parties on RNCs? and (3) What percent of RNCs could be prevented by the direct project team? The aim of the research was to determine the main sources, responsible parties and RNC types affecting construction projects, using standardized information captured by the software. A database comprised weekly information from the entire execution scope of 25 high-rise building and 25 industrial construction projects, carried out by 12 Chilean construction companies between 2012 and 2019, was used to assess RNC relevance, composition and impact. The sample was first used in research presented at IGLC28 (Lagos et al., 2020; Lagos \& Alarcón, 2020).

\section{COLLECTION AND STANDARDIZATION OF INFORMATION}

Standardized information tables regarding the plan, tasks, short-term periods and RNCs were obtained for each project. The plan table contained the type of the project, it's ID, it's initially planned start and end dates, and its actual start and end dates. The tasks table contained a detailed log, including the ID, initial planned dates, current planned dates and the initial, committed and actual progress, of each task in each short-term period of each project. The RNCs table included their ID, the affected task ID, project ID, date of occurrence, type, detailed description and responsible party registered by the project's team for each issue. This information allowed to categorize each RNC, link it to a specific task in a certain short-term period and determine their impact.

The RNCs types were consolidated based on the detailed information available and assigned into eight categories based on the seven flows (Koskela, 2008): Labour, Supply, Worksite Conditions, Productivity, Planning, Engineering and Design, Unforeseen events, and Quality. The responsible parties were classified into four categories, based on similarities of the distinct party registered and the details provided: Main Contractor, Subcontractors, Client, and Third Parties, such as suppliers or external agents. Finally, the sources were categorized as: Internal, if the Main Contractor's direct team could have prevented the issue, or External if it could not have been controlled by them. The sources were determined based on the RNC and affected task details.

\section{ASSESSMENT OF RNC COMPOSITION AND IMPACT}

Each project was assessed separately to determine the relevance of each RNC category. The indicator "Relative Frequency Index" (RFI) was calculated in each project as the 
percent of RNCs belonging to each the category, to assess composition. The Task-Days Impact indicator (TDI), which represented the delay in days caused by a single RNC in a specific task was used to represent the impact of each RNC in the project. The TDI was calculated as the percent difference between commitment and progress, multiplied by the duration of the task. The sum of the TDIs from a specific category in a project was divided by the sum of all its RNC's TDIs to obtain an impact indicator for each category, called the Relative Impact Index (RII). Table 1 shows the calculation of these metrics.

Table 1. Description of RNC metrics

\begin{tabular}{|c|c|c|}
\hline RNC Metric & Indicator & Description \\
\hline Frequency & $\mathrm{N}^{\circ} \mathrm{RNC}$ & $N^{\circ} R N C s_{\text {Categoryi }}$ \\
\hline Impact & Task-Days Impact & $T D I=\left(\right.$ Planned $_{\%}-$ Actual $\left._{\%}\right) *$ Duration $_{\text {task }}$ \\
\hline Composition & Relative Frequency Index & $R F I=\frac{N^{\circ} R N C s_{\text {Category } i}}{\text { Total } N^{\circ} R N C s_{\text {Project } j}}$ \\
\hline Relevance & Relative Impact Index & $T D I=\frac{\sum_{R N C s \text { in category } i} T D I_{R N C j}}{\sum_{\text {All the RNCs in the project }} T D I_{R N C k}}$ \\
\hline
\end{tabular}

\section{Analysis of Differences Between Projects and RNC Categories}

The project types were compared using the average RFI and RII from each group. The normality of each project type sample was assessed using the Shapiro-Wilk's Test (Lagos \& Alarcón, 2020). The null hypothesis "the sample follows a normal distribution" was established using a 95\% confidence level, so if any of the samples obtained a pvalue $\leq 0.05$ it meant that it did not follow a normal distribution. If both samples followed a normal distribution, the t-test was used to determine the statistical significance of the differences and, if any of the samples was not normal, the non-parametric Mann Whitney's U test was used instead. In both cases, the null hypothesis "the samples do not present significant differences" was rejected if p>0.05 (Hernández et al., 2006). The RFI and RII from two or more categories within a project type and in the entire sample are codependent variables, since an increase in the percent relevance of a category implies a decrease in the relative relevance of the rest of the categories. Hence, the $\mathrm{N}^{\circ}$ of RNCs in each category and the sum of their TDIs, which are independent variables, were used to compare categories against each other. The same process was followed to assess the normality and statistical significance of the observed differences.

\section{RESULTS AND DISCUSSION}

The study sample represented 22.636 RNCs from 50 projects, with a minimum of 22 RNCs a maximum of 2845 RNCs per project. The average number of RNCs per shortterm period was 9.8, with a minimum of 1.2 RNCs per week and a maximum of 44.1. This section addresses the three research questions separately.

\section{WHICH ARE THE MOST RELEVANT RNC TYPES?}

Table 2 shows that labour, supply and worksite conditions represented approximately 55\% of the issues and impact in the entire sample. Also, labour, productivity, planning, quality and worksite conditions, which are potentially controllable issues, accounted for approximately $66 \%$ of the issues and impact. Although, as Table 3 presents, significant differences were found in RNC composition between HR and IC projects. Controllable 
types represented $79 \%$ of RNCs and $82 \%$ impact in HR projects, while only $53 \%$ and $52 \%$ in IC projects, respectively: However, these results were consistent with the hypothesis.

Table 1 . RNC types by frequency and impact

\begin{tabular}{ccc}
\hline RNC Type & RFI average & RII average \\
\hline Labour & $20,7 \%$ & $22,4 \%$ \\
Supply & $17,2 \%$ & $16,9 \%$ \\
Worksite conditions & $16,9 \%$ & $16,5 \%$ \\
Productivity & $13,1 \%$ & $12,1 \%$ \\
Planning & $11,2 \%$ & $10,8 \%$ \\
Engineering and Design & $10,3 \%$ & $11,4 \%$ \\
Unforeseen events & $6,2 \%$ & $6,0 \%$ \\
Quality & $4,4 \%$ & $3,8 \%$ \\
\hline
\end{tabular}

Labour and productivity issues were significantly greater in HR projects, while the main issues in IC were Worksite Conditions, Supply and Engineering-Design. These differences can be explained by the nature and conditions of execution in each project type. The IC projects in the sample were brownfields executed in mining or productive sites far from urban locations, meaning that they were carried out while the client continued operations and the supply of resources required longer times. Also, Engineering-Design was provided by the client. In comparison, HR projects were mostly executed in large or mid-size cities, on sites owned by the Contractor or Realtor and with Engineering-Design provided beforehand either by the Realtor or the Contractor. Hence, external and uncontrollable factors were less likely to impact production in HR projects.

Table 2. Comparison of RNC types in HR and IC projects

\begin{tabular}{|c|c|c|c|c|c|c|c|c|}
\hline \multirow[t]{2}{*}{ RNC Type } & \multicolumn{4}{|c|}{ RFI } & \multicolumn{4}{|c|}{ RII } \\
\hline & HR & IC & Delta & p-value & HR & IC & Delta & $p$-value \\
\hline Engineering-Design & $3 \%$ & $17 \%$ & $-80 \%$ & 0,00 & $4 \%$ & $19 \%$ & $-79 \%$ & 0,00 \\
\hline Labour & $33 \%$ & $9 \%$ & $280 \%$ & 0,00 & $37 \%$ & $8 \%$ & $340 \%$ & 0,00 \\
\hline Planning & $11 \%$ & $12 \%$ & $-7 \%$ & 0,44 & $11 \%$ & $11 \%$ & $-5 \%$ & 0,34 \\
\hline Productivity & $17 \%$ & $9 \%$ & $96 \%$ & 0,02 & $16 \%$ & $8 \%$ & $108 \%$ & 0,02 \\
\hline Quality & $7 \%$ & $1 \%$ & $429 \%$ & 0,00 & $6 \%$ & $2 \%$ & $300 \%$ & 0,00 \\
\hline Supply & $14 \%$ & $21 \%$ & $-32 \%$ & 0,02 & $13 \%$ & $20 \%$ & $-34 \%$ & 0,03 \\
\hline Unforeseen events & $3 \%$ & $10 \%$ & $-69 \%$ & 0,03 & $3 \%$ & $9 \%$ & $-71 \%$ & 0,04 \\
\hline Worksite conditions & $11 \%$ & $22 \%$ & $-49 \%$ & 0,01 & $11 \%$ & $23 \%$ & $-53 \%$ & 0,00 \\
\hline
\end{tabular}

\section{What is The Relative ImPaCt Of Different Parties on RNCs?}

Table 4 shows that the Main Contractor and Subcontractor accounted for $74 \%$ of the RNCs and $75 \%$ of their impact over the entire sample. Hence, the Client and Third parties contributed significantly less to performance issues than the on-site project team. Although, Table 5 shows differences consistent with the findings from the previous question. The Main Contractor and its Subcontractors produced approximately $96 \%$ of 
issues in HR projects, while in IC projects, they were responsible for $54 \%$ of the RNCs and $55 \%$ of their impact. These results still corroborate the hypothesis that most issues could potentially be controlled by the direct team, but two findings are worth discussing in more detail.

Table 3. Composition and impact by RNC responsible party

\begin{tabular}{ccccc}
\hline RNC Metrics & Main Contractor & Subcontractor & Client & Third Parties \\
\hline RFI & $45 \%$ & $29 \%$ & $18 \%$ & $8 \%$ \\
RII & $45 \%$ & $30 \%$ & $16 \%$ & $9 \%$ \\
\hline
\end{tabular}

First, Subcontractors had a significantly greater impact on HR projects than the Main Contractor and, second, the client was responsible for almost a third of the RNCs in IC project; both results are consistent with the literature findings. A recent study observed that parties tended to act as autonomous agents, unless the Main Contractor ensured a clear understanding of roles and objectives of collaborative LPS instances (Rincón et al., 2019). Thus, if the client and subcontractors are not actively involved in planning and continual improvement, they operate separately from the core team, contributing to noncompliance instances. Transparency, direct communication and collaboration incentives are key to sustain efficient constraint management and RNC removal processes (Brady et al., 2011), therefore, if project teams fail to make constraints and RNC sources explicit, they fail to work as a single interrelated chain of commitments (Porwal, 2010).

Table 4. Comparison of the relevance of each party between HR and IC projects

\begin{tabular}{c|cccc|cccc}
\hline \multirow{2}{*}{ Responsible parties } & \multicolumn{4}{|c|}{ RFI } & \multicolumn{4}{c}{ RII } \\
\cline { 2 - 9 } & HR & IC & Delta & p-value & HR & IC & Delta & p-value \\
\hline Client & $1 \%$ & $\mathbf{3 4} \%$ & $-96 \%$ & 0,00 & $2 \%$ & $\mathbf{3 1} \%$ & $-95 \%$ & 0,00 \\
Main Contractor & $\mathbf{4 1 \%}$ & $\mathbf{5 0} \%$ & $-19 \%$ & 0,11 & $\mathbf{3 9} \%$ & $\mathbf{5 1} \%$ & $-24 \%$ & 0,05 \\
Subcontractor & $\mathbf{5 5 \%}$ & $\mathbf{4} \%$ & $1342 \%$ & $\mathbf{0 , 0 0}$ & $\mathbf{5 7 \%}$ & $\mathbf{4} \%$ & $\mathbf{1 3 9 5 \%}$ & $\mathbf{0 , 0 0}$ \\
Third parties & $3 \%$ & $12 \%$ & $-75 \%$ & 0,13 & $3 \%$ & $\mathbf{1 5} \%$ & $-81 \%$ & 0,07 \\
\hline
\end{tabular}

\section{WHAT PERCENT OF RNCS ARE CONTROLLABLE BY THE PROJECT TEAM?}

Table 6 shows that internal RNC sources were slightly more predominant than external causes, however, the differences were not sufficient to exhibit statistical significance. These results indicate that sources controllable by the Main Contractor are at least as relevant as external sources in terms of frequency and performance impacts. Table 7 shows that internal sources were also slightly more predominant in HR than in IC projects, which is consistent with the previous findings, although, the differences between the project groups were not statistically significant. Finally, Table 8 shows that internal RNCs were $20 \%$ more frequent but only caused $10 \%$ more impact, without exhibiting statistically significant differences. These results allowed to conclude that the Main Contractor should be able to prevent at least half of the RNCs observed, but the findings from previous sections demonstrate that close collaboration with the Client and Subcontractors could help to prevent almost $90 \%$ of the sources of noncompliance. 
Table 6. RNC source analysis

\begin{tabular}{ccccc}
\hline RNC metrics & Internal & External & Difference & p-value \\
\hline N $^{\circ}$ RNCs & 252 & 201 & $20 \%$ & 0.13 \\
TDI sum & 1435 & 1294 & $10 \%$ & 0.27 \\
\hline
\end{tabular}

Table 7. Source comparison between HR and IC projects

\begin{tabular}{c|cccc|cccc}
\hline \multirow{2}{*}{ Responsible parties } & \multicolumn{4}{|c|}{ RFI } & \multicolumn{4}{c}{ RII } \\
\cline { 2 - 9 } & HR & IC & Delta & p-value & HR & IC & Delta & p-value \\
\hline Internal & $\mathbf{5 8 \%}$ & $\mathbf{5 3} \%$ & $9 \%$ & 0,38 & $\mathbf{5 5} \%$ & $\mathbf{5 3} \%$ & $4 \%$ & 0,73 \\
External & $42 \%$ & $47 \%$ & $-10 \%$ & 0,38 & $45 \%$ & $47 \%$ & $-4 \%$ & 0,73 \\
\hline
\end{tabular}

Table 8. Comparison of internal and external sources within each project category

\begin{tabular}{c|cccc|cccc}
\hline \multirow{2}{*}{ Metrics } & \multicolumn{4}{|c|}{ HR } & \multicolumn{4}{c}{ IC } \\
\cline { 2 - 9 } & Internal & External & Delta & p-value & Internal & External & Delta & p-value \\
\hline N $^{\circ}$ RNCs & 408 & 322 & $27 \%$ & 0.16 & 95 & 79 & $20 \%$ & 0.22 \\
TDI Sum & 2301 & 2092 & $10 \%$ & 0.25 & 569 & 492 & $16 \%$ & 0.30 \\
\hline
\end{tabular}

\section{CONCLUSIONS}

This research aimed to determine the most relevant RNCs categories affecting LPS projects. 22.636 RNCs from 25 high-rise building (HR) and 25 industrial construction (IC) projects were assessed qualitatively and quantitatively to determine the frequency and impact of 8 types, 4 responsible parties and 2 sources of noncompliance. The results showed that two thirds of all the RNCs assessed belonged to types controllable by the core project team. Moreover, approximately $80 \%$ of RNCs corresponded to potentially controllable issues in HR projects. The RNCs type differences exhibited between HR and IC projects were explained by the nature and conditions of each project category.

The responsible party analyses were consistent with the previous findings and indicated that approximately $90 \%$ of issues were caused by the Main Contractor or its Subcontractors in HR projects, while they were responsible for approximately $55 \%$ of the RNCs in the IC sample. The second most relevant party in IC projects was the Client, who was responsible for one in every three issues. Moreover, the source analyses showed that the Main Contractor could have potentially prevented at least half of the RNCs, but that percent could be increased to over $85 \%$ of issues if they collaborate closely with the Client and Subcontractors through transparency, direct communication and implementation of correct incentives. Finally, the authors suggest that this research should be continued by expanding the sample, to allow assessing key differences in RNC composition and impact between projects with high- and low-performance and finding means to prevent RNCs.

\section{ACKNOWLEDGEMENTS}

The authors would like to acknowledge ANID for financial support for this study through project Fondecyt $\mathrm{N}^{\circ} 1210769$ and CONICYT Ph.D. Scholarship No21181603. In addition, we would like to thank the Production Management Centre (GEPUC) from the Pontificia Universidad Católica de Chile for allowing access to the project database from IMPERA. 


\section{REFERENCES}

Akinsiku, O., \& Akinsulire, A. (2012). Stakeholders' Perception of the Causes and Effects of Construction Delays on Project Delivery. KICEM Journal of Construction Engineering and Project Management.

Alarcón, L. F., \& Calderón, R. (2003). A production planning support system for construction projects. 11th Annual Conference of the International Group for Lean Construction. Virginia, USA.

Alsehaimi, A. O., Fazenda, P. T., \& Koskela, L. (2014). Improving construction management practice with the Last Planner System: A case study. Engineering, Construction and Architectural Management, 21(1), 51-64.

Arditi, D., Akan, G. T., \& Gurdamar, S. (1985). Reasons for delays in public projects in Turkey. Construction Management and Economics, 3(2), 171-181.

Assaf, S. A., \& Al-Hejji, S. (2006). Causes of delay in large construction projects. International Journal of Project Management, 24(4), 349-357. doi.org/10.1016/j.ijproman.2005.11.010.

Ballard, G., Hammond, J., \& Nickerson, R. (2009). Production control principles. Proceedings of IGLC17: 17th Annual Conference of the International Group for Lean Construction, 489-500.

Ballard, G., \& Tommelein, I. (2016). Current Process Benchmark for the Last Planner System. Lean Construction Journal, 13(1), 57-89.

Bortolazza, R., \& Formoso, C. (2006). A Quantitative Analysis of Data Collected From the Last Planner System in Brazil. 14th Annual Conference of the International Group for Lean Construction Santiago de Chile, 625-635.

Brady, D., Tzortopoulos, P., \& Rooke, J. (2011). an Examination of the Barriers To Last Planner Implementation. 19th Annual Conference of the International Group for Lean Construction, 13-15.

Daniel, E., Pasquire, C., \& Dickens, G. (2015). Exploring the Implementation of the Last Planner ${ }^{\circledR}$ System Through Iglc Community: Twenty One Years of Experience. Proceedings for the 23rd Annual Conference of the International Group for Lean Construction, Perth, Australia., February 2016, 153-162.

Dave, B., Boddy, S., \& Koskela, L. (2010). Improving information flow within the production management system with web services. 18th Annual Conference of the International Group for Lean Construction, 445-455.

Dave, B., Hämäläinen, J.-P., \& Koskela, L. (2015). Exploring the Recurrent Problems in the Last Planner Implementation on Construction Projects. Proceedings of the Indian Lean Construction Conference (ILCC 2015), 1-9.

Faloughi, M., Bechara, W., Chamoun, J., \& Hamzeh, F. (2014). SimpLean: An Effective Tool for Optimizing Construction Workflow. Proceedings for the 22nd Annual Conference of the International Group for Lean Construction, 281-292.

Feliz, T., Reed, D., Draper, J., \& Macomber, H. (2014). Leveraging software for learningin-action using commitment-based planning. 22nd Annual Conference of the International Group for Lean Construction: Understanding and Improving Project Based Production, IGLC 2014, 1307-1318.

Formoso, C. T., \& Moura, C. B. (2009). Evaluation of the impact of the Last Planner system on the performance of construction projects. Proceedings of IGLC17: 17th Annual Conference of the International Group for Lean Construction, 153-164.

Gao, S., \& Low, S. P. (2014). The Last Planner System in China's construction industry - A SWOT analysis on implementation. International Journal of Project 
Management, 32(7), 1260-1272.

Hamzeh, F., \& Aridi, O. (2013). Modeling the last planner system metrics: a case study of an aec company. Proceedings for the 21th Annual Conference of the International Group for Lean Construction. Fortaleza, Brazil, 599-608.

Henrich, G., Bertelsen, S., Koskela, L., Kraemer, K., Rooke, J., \& Owen, R. (2007). Construction Physics. 15th IGLC - International Group for Lean Construction Conference, 1-14.

Hernández, R., Fernández, C., \& Baptista, P. (2006). Metodología de la investigación. In McGraw-Hill Interametricana.

Kim, Y. W. (2019). The impact of make-ready process on project cost performance in heavy civil construction projects. Production Planning and Control, 30(13), 10641071.

Lagos, C., \& Alarcón, L. F. (2020). Using Percent Plan Completed for Early Success Assessment in the Last Planner System. In I. Tommelein \& E. Daniel (Eds.), Proc. 28th Annual Conference of the International. Group for Lean Construction (IGLC28).

Lagos, C., Alarcón, L. F., Basoalto, F., \& Del Río, Ó. (2020). Using Reasons for NonCompliance To Assess Project Performance in the Last Planner System. In I. Tommelein \& E. Daniel (Eds.), Proc. 28th Annual Conference of the International. Group for Lean Construction (IGLC28).

Lagos, C., Herrera, R. F., \& Alarcón, L. F. (2019). Assessing the Impacts of an IT LPS Support System on Schedule Accomplishment in Construction Projects. Journal of Construction Engineering and Management, 145(10), 1-10. doi.org/10.1061/(ASCE)CO.1943-7862.0001691.

Porwal, V. (2010). Last Planer System - Areas of application and implementation challenges. Texas A\&M University.

Prasad, K. V., \& Vasugi, V. (2017). Delays in construction projects: A review of causes, need and scope for further research. Malaysian Construction Research Journal, 23(3), 89-113.

Rincón, J. L., Fernández-Solís, J. L., Lavy, S., \& Du, J. (2019). Effect of Autonomous Agents on Last Planner System Performance in Texas. Journal of Management in Engineering, 35(1), 04018050. https://doi.org/10.1061/(asce)me.19435479.0000657

Sambasivan, M., \& Soon, Y. W. (2007). Causes and effects of delays in Malaysian construction industry. International Journal of Project Management, 25(5), 517526. doi.org/10.1016/j.ijproman.2006.11.007.

Soares, A., Bernardes, M., \& Formoso, C. (2002). Improving the production planning and control system in a building company: Contributions after stabilization. Annual Conference of the International Group for Lean Construction, 10, 1-12.

Tayeh, B. A., Hallaq, K. Al, Zahoor, H., \& Al Faqawi, A. H. (2019). Techniques and benefits of implementing the last planner system in the Gaza Strip construction industry. Engineering, Construction and Architectural Management, 26(7), 14241436. doi.org/10.1108/ECAM-01-2018-0039.

Ullah, K., Abdullah, A. H., Nagapan, S., Suhoo, S., \& Khan, M. S. (2017). Theoretical framework of the causes of construction time and cost overruns. IOP Conference Series: Materials Science and Engineering, 271(1). doi.org/10.1088/1757899X/271/1/012032. 